Article

\title{
Formulation and Characterization of Native and Crosslinked Hyaluronic Acid Microspheres for Dermal Delivery of Sodium Ascorbyl Phosphate: A Comparative Study
}

\author{
Arianna Fallacara 1,2,3 ${ }^{\mathbb{D}}$, Filippo Marchetti ${ }^{1}$, Michele Pozzoli ${ }^{2}$, Ugo Raffaello Citernesi ${ }^{3}$, \\ Stefano Manfredini ${ }^{1,4, *(1)}$ and Silvia Vertuani ${ }^{1,4}$ \\ 1 Department of Life Sciences and Biotechnology, Master Course in Cosmetic Science and \\ Technology (COSMAST), University of Ferrara, Via Luigi Borsari 46, 44121 Ferrara (FE), Italy; \\ fllrnn@unife.it (A.F.); filippo.marchetti@student.unife.it (F.M.); vrs@unife.it (S.V.) \\ 2 Respiratory Technology, Woolcock Institute of Medical Research and Discipline of Pharmacology, \\ Faculty of Medicine and Health, The University of Sydney, 431 Glebe Point Road, Glebe, NSW 2037, \\ Australia; michele.pozzoli@sydney.edu.au \\ 3 I.R.A. Istituto Ricerche Applicate s.r.l., Via Del Lavoro 4a/6, 20865 Usmate-Velate (MB), Italy; \\ citernesi@iralab.it \\ 4 Ambrosialab Srl, Via Mortara 171, 44121 Ferrara (FE), Italy \\ * Correspondence: smanfred@unife.it; Tel.: +39-0532-455-294; Fax: +39-0532-455-378
}

Received: 27 October 2018; Accepted: 26 November 2018; Published: 1 December 2018

\begin{abstract}
The present work evaluates for the first time the use of urea-crosslinked hyaluronic acid (HA-CL), a novel derivative of native hyaluronic acid (HA), to produce microspheres (MS) by emulsification-solvent evaporation, for dermal delivery of sodium ascorbyl phosphate (SAP). As the term of comparison, HA MS were prepared. A pre-formulation study-investigation of the effects of polymers solutions properties ( $\mathrm{pH}$, viscosity) and working conditions-led to the production of optimized HA-CL MS and HA-CL-SAP MS with: almost unimodal size distributions; mean diameter of $13.0 \pm 0.7$ and $9.9 \pm 0.8 \mu \mathrm{m}$, respectively; spherical shape and rough surface; high yield, similar to HA MS and HA-SAP MS $(\approx 85 \%)$. SAP was more efficiently encapsulated into HA-CL MS $(78.8 \pm 2.6 \%)$ compared to HA MS $(69.7 \pm 4.6 \%)$. Physical state, thermal properties, relative moisture stability of HA-CL MS and HA-CL-SAP MS were comparable to those of HA MS and HA-SAP MS. However, HA-CL-SAP MS exhibited an extended drug release compared to HA-SAP MS, despite the same kinetic mechanism-contemporaneous drug diffusion and polymer swelling/dissolution. Therefore, HA-CL formulation showed a greater potential as microcarrier (for encapsulation efficiency and release kinetic), that could be improved, in future, using suitable excipients.
\end{abstract}

Keywords: dermal delivery; drug release; hyaluronic acid; urea-crosslinked hyaluronic acid; microspheres; sodium ascorbyl phosphate

\section{Introduction}

Hyaluronic acid (HA) is a naturally occurring glycosaminoglycan, pervasively diffused in the human body: it is found in the extracellular matrix, skin dermis, eye vitreous, hyaline cartilage, synovial fluid, and umbilical cord. HA is well known for its numerous biological functions [1,2] and its interesting properties such as biocompatibility, biodegradability, and mucoadhesion [3,4]. Moreover, HA has moisturizing, lubricant, and filler actions, and it is involved in wound healing and anti-inflammatory processes [1,3]. For these reasons, hyaluronan has widespread applications in medical, pharmaceutical, 
and cosmetic fields, and represents an interesting starting material-frequently combined to other active ingredients or excipients-in tissue engineering, viscosupplementation, and drug delivery [1,3-12]. To design biomaterials with improved physical-chemical, viscoelastic, and biological properties, native HA is often subjected to derivatization or crosslinking [13]. Usually, HA is crosslinked with difunctional molecules of synthetic origin, for example, divinyl sulfone and diglycidyl ether $[14,15]$. Nevertheless, the recent trend consists in crosslinking the polymer with substances characterized by lower toxicity and intrinsic health activity. The aim is to obtain cross-polymers that can act as multifunctional molecules able to deliver active ingredients and to exert, at the same time, a health action [1]. Toward this end, we are actually investigating the possible pharmaceutical, cosmetic, and aesthetic applications of the new HA crosslinked with urea (HA-CL) [9,16-18]. HA-CL is a recently patented biocompatible and biodegradable polymer, provided with greater consistency and bioactivity with respect to native HA $[9,16,18]$. This is due to hyaluronan crosslinking with urea, a molecule naturally present in the human body and also employed as active substance. Indeed, urea is widely and safely used in pharmaceutical and cosmetic formulations because it is keratolytic and moisturizing, and thus it enhances cellular regeneration and repair. Urea is useful to treat different diseases, such as dry skin, damaged cutaneous annexes, non-infectious keratopathy, and injured corneal epithelium [19-21]. Hence, HA-CL could be a promising biomaterial for topical treatments requiring simultaneous re-epithelialization and hydration for the resolution of aesthetic/functional skin and mucosae problems $[9,16,17]$.

Biodegradable and mucoadhesive polymers, in the form of microparticulate systems such as microspheres (MS), can accelerate skin wound healing [22] and extend the release of the encapsulated drugs $[8,23,24]$. Acknowledging the aforementioned facts and properties of HA-CL, we decided to explore for the first time, with this work, the potentiality of HA-CL to formulate drug loaded MS intended for the dermal target. The preparative method chosen was a water-in-oil (w/o) emulsification solvent evaporation technique, and native HA was used as reference polymer, as it has been already employed to produce MS [8,11]. This study has as its goal the provision of the perfect case scenario: to have an active molecule, never loaded before into hyaluronan microcarriers, which could be satisfyingly encapsulated and then freely released by the MS. Therefore, sodium ascorbyl phosphate (SAP) was selected as the model drug for its high hydrophilicity [25] and for its unprecedented encapsulation into hyaluronan MS. Moreover, SAP seemed to be an optimal candidate as it is characterized by good physical-chemical stability instead of ascorbic acid, and by several biological activities which go in synergy with those of HA. Indeed, SAP acts as a radical scavenger, with high capacity to reduce damages caused by photo-oxidation and lipid peroxidation, and it has strong antimicrobial activity on Propionibacterium acnes, the major bacterium responsible of acne vulgaris $[25,26]$. The SAP is a non-irritating prodrug bioconverted by skin enzymes into ascorbic acid, which stimulates collagen synthesis and, therefore, increases skin elasticity $[27,28]$. Hence, the combination of vitamin $C$ derivatives and hyaluronan could open interesting perspectives. In fact, a recent study reported the safety of an HA sponge system containing a derivative of vitamin $C$ used to reduce and treat scars [27]. Additionally, the delivery of a combination of SAP and HA-CL showed enhanced anti-inflammatory and antioxidant activities with respect to the single SAP and HA-CL: hence, the association of SAP and HA-CL could be suitable as an adjunctive therapy for the treatment of inflammatory pulmonary disorders [18].

In this research, SAP-loaded hyaluronan MS were formulated using the novel urea-crosslinked hyaluronic acid. A pre-formulation study was carried out to obtain optimized MS: particle features such as mean diameter, size distribution, yield (Y\%), drug loading (DL\%), and encapsulation efficiency $(\mathrm{EE} \%)$ were investigated in relation to the properties of the starting polymeric solutions and to the emulsification time. The optimized MS were then characterized more in detail for their physical-chemical properties-morphology, physical state, thermal behavior, moisture sorption, and stability—and for their in vitro release profiles. An accurate and itemized theoretical study was performed to understand and explain, with a systematic approach, the mechanisms of release and the experimental features of HA-CL 
formulations. Considering that this was the first research describing HA-CL MS, no excipients were added to the formulations, in order to investigate the actual polymer potentiality as microcarrier. Furthermore, all the properties of SAP-loaded as well as unloaded MS of HA-CL were compared to SAP-loaded and unloaded MS of native HA (prepared as reference formulations).

\section{Materials and Methods}

\subsection{Materials}

Native hyaluronic acid (sodium salt, molecular weight 1.2 MDa) and urea-crosslinked hyaluronic acid (molecular weight 2.0-4.0 MDa -raw material containing also pentylene glycol) were kindly given by I.R.A. Srl (Istituto Ricerche Applicate Srl, Usmate-Velate, Monza-Brianza, Italy). Sodium ascorbyl phosphate (known under the trade name STAY-C ${ }^{\circledR} 50$ ) was purchased from DSM Nutritional Products Ltd. (Segrate, Milano, Italy). Phosphate buffered saline (PBS) and hexane were supplied by Sigma-Aldrich (Schnelldorf, Germany). Mineral oil was obtained from Fagron (Quarto Inferiore, Bologna, Italy). Sorbitan monooleate (Span 80) was provided by Acef (Fiorenzuola D’Arda, Piacenza, Italy).

\subsection{Prepair of Hyaluronan and Hyaluronan-SAP Solutions (Aqueous Phases)}

HA $1 \%(w / v)$ solution and HA-CL $1 \%(w / v)$ solution were achieved through a progressive dispersion of the polymers in deionized water, under continuous magnetic stirring (300 rpm). Likewise, hyaluronan-SAP solutions $1 \%(w / v), 1: 1$, were prepared by dispersing the polymers into SAP water solutions, under constant magnetic stirring (300 rpm). The polymers were allowed to completely hydrate thus forming hydrogels, which were left to swell under moderate stirring, over $12 \mathrm{~h}$, at room temperature, to reach homogeneous appearances. The gels were left at rest for $12 \mathrm{~h}$ prior to examinations or use as aqueous phases for MS formulation.

\subsection{Characterization of Hyaluronan and Hyaluronan-SAP Solutions: $p H$ and Rheology}

Firstly, the $\mathrm{pH}$ of each hyaluronan aqueous phase was measured in triplicate using a digital $\mathrm{pH}$ meter (Docu pH+ meter, Sartorius Mechatronics, Goettingen, Germany).

Secondly, hyaluronan hydrogels were subjected to rheological analyses, performed in triplicate, at $23 \pm 2{ }^{\circ} \mathrm{C}$, with a rotational rheometer AR2000 (TA Instruments, New Castle, DE, USA), equipped with an aluminum cone/plate geometry-diameter $40 \mathrm{~mm}$, angle $2^{\circ}, 64 \mu \mathrm{m}$ truncation. A solvent trap was used in order to prevent samples dehydration. The rheometer was connected to the Rheology Advantage software (version V7.20) for data analysis.

Flow measurements were performed by a shear rate sweep, under steady state condition: after 1 -min equilibration time, the shear rate $(\dot{\gamma})$ was progressively increased from 0.01 to $1000 \mathrm{~s}^{-1}$. The gels were compared for their zero-shear-rate viscosity $\left(\eta_{0}\right)$, which was determined by fitting the viscosity curves according to the Cross equation [29] (Equation (1)):

$$
\eta=\eta_{\infty}+\frac{\eta_{0}-\eta_{\infty}}{1+(C \cdot \dot{\gamma})^{n}}
$$

where $\eta$ is the viscosity at a given shear rate (Pa.s), $\dot{\gamma}$ is the shear rate $\left(\mathrm{s}^{-1}\right), \eta_{0}$ is the zero-shear-rate viscosity (Pa.s), $\eta_{\infty}$ is the infinite-shear-rate viscosity (Pa.s), $C$ is a multiplicative parameter (s) and $n$ is a dimensionless exponent.

Oscillatory measurements were then taken under the constant stress value of $0.2 \mathrm{~Pa}$, which belonged to the viscoelastic linear regime (defined by a strain sweep test), where the hydrogels could not be subjected to irreversible structural modifications. The experiments were carried out with oscillation frequencies ranging from 0.01 to $100 \mathrm{~Hz}$. The elastic modulus $\left(G^{\prime}\right)$ and the viscous modulus $\left(G^{\prime \prime}\right)$, measured as a function of the frequency of the stress applied, allowed to evaluate the viscoelastic properties of the gels [30]. More precisely, the samples were compared for their elastic modulus at 
$1 \mathrm{~Hz}\left(G_{1 H z}^{\prime}\right.$, quantitative index of elasticity), and for their crossover frequency $\left(C_{f}\right.$, a frequency where $G^{\prime}$ is equal to $G^{\prime \prime}$ ).

\subsection{Formulation of HA and HA-CL Microspheres Containing or not SAP}

HA and HA-CL MS containing or not SAP were produced through a water-in-oil (w/o) emulsification solvent evaporation technique, adapted from the method described by Lim and co-workers [11].

The aqueous phase was added dropwise (flow rate: $0.91 \mathrm{~mL} / \mathrm{min}$ ) into $100 \mathrm{~g}$ of mineral oil (oil phase) containing $1 \%(w / w)$ sorbitan monooleate as the emulsifying agent, under moderate magnetic stirring (200 rpm), at $23 \pm 2{ }^{\circ} \mathrm{C}$. The aqueous phase was then emulsified at $1000 \mathrm{rpm}$, at $23 \pm 2{ }^{\circ} \mathrm{C}$, into the oil phase, using a Silverson L5M A Laboratory Mixer (Silverson Machines, Buckinghamshire, United Kingdom), equipped with a fine emulsor screen workhead. Different emulsification times of 10, 30 and 60 min were investigated. Afterward, moderate magnetic stirring (200 rpm) and mild heating $\left(37 \pm 2{ }^{\circ} \mathrm{C}\right)$ were constantly maintained for $12 \mathrm{~h}$ to guarantee the complete evaporation of the dispersed aqueous phase. The MSs thus formed were separated from the oil phase by centrifugation at $4000 \mathrm{rpm}$, at $23 \pm 2{ }^{\circ} \mathrm{C}$, for $30 \mathrm{~min}$ (ALC Centrifuge PK110, OPTO-LAB, Concordia sulla Secchia, Modena, Italy). The pellets were resuspended in hexane and filtered under vacuum, at $23 \pm 2{ }^{\circ} \mathrm{C}$, using a Millipore glass filtration system, equipped with a polyamide membrane, pore size $0.22 \mu \mathrm{m}$ (Sartorius, Muggiò, Monza-Brianza, Italy). The collected MSs were finally dried in an oven at $37 \pm 2{ }^{\circ} \mathrm{C}$ for $12 \mathrm{~h}$.

\subsection{MS Yield, Drug Loading, and Encapsulation Efficiency}

MS yield (Y\%), drug loading (DL\%) and drug encapsulation efficiency (EE\%) were respectively calculated from Equations (2)-(4)

$$
Y \%=\frac{\text { weight of recovered MS }}{\text { weight of polymer } * \text { and drug fed initially }} \cdot 100
$$

${ }^{*}$ HA-CL was provided as a raw material containing pentylene glycol. Being hydrophilic, this excipient was taken into account for the determination of HA-CL MS Y\%, because 1\% (w/v) HA-CL solutions contained $0.75 \%(w / v)$ pentylene glycol.

$$
\begin{gathered}
D L \%=\frac{\text { weight of drug in } M S}{\text { weight of recovered } M S} \cdot 100 \\
E E \%=\frac{\text { weight of drug in } M S}{\text { weight of drug fed initially }} \cdot 100
\end{gathered}
$$

For each MS formulation, all the determinations were performed in triplicate and the results were reported as the mean \pm standard deviation (SD).

The amount of encapsulated drug was determined by completely dissolving $30 \mathrm{mg}$ of SAP loaded MS in $300 \mathrm{~mL}$ of release medium. Drug concentration was then assayed by ultraviolet (UV) spectroscopy (SHIMADZU UV-2600 spectrophotometer, Kyoto, Japan), at $258 \mathrm{~nm}$ (wavelength value corresponding to SAP $\lambda$ max), on the basis of a previously plotted calibration curve. Unloaded HA and HA-CL MS were tested to ensure that other components of the formulations were not characterized by UV absorbance at the scanning wavelength.

\subsection{Particle Size Analysis}

Particle size distributions of HA and HA-CL microspheres containing or not SAP were analyzed using laser diffraction (Malvern Mastersizer 2000, Malvern Instruments Ltd., Malvern, UK). Samples of powder (ca. $10 \mathrm{mg}$ ) were dispersed through the Scirocco dry dispersion unit (Malvern, UK) with a feed pressure of 4 bars and a feed rate of $100 \%$. Samples were analyzed in triplicate, with an obscuration value between $0.1 \%$ and $15 \%$ and a reference refractive index of 1.33 . The volume weighted mean 
diameters (D [3,4]) and the median particle size by volume Dv50 were used to describe MS size. Size distributions were evaluated by calculation of samples Span values as (Equation (5))

$$
\text { Span }=\frac{D v 90-D v 10}{D v 50}
$$

where $D v 90, D v 10$, and $D v 50$ are respectively the $90 \%, 10 \%$ and $50 \%$ cumulative volume distributions. Thus, the Span values gave a measure of the ranges of the volume distributions relative to the median diameters.

\subsection{SEM Morphological Analysis}

The morphology (shape and surface) of HA and HA-CL MS containing or not SAP was observed using a field emission scanning electron microscope (Zeiss EVO 40XVP, Carl Zeiss Pty Ltd., Oberkochen, Germany), with an acceleration voltage of $20 \mathrm{kV}$. Powder samples were deposited on carbon sticky tabs and sputter coated with a thin layer of gold-palladium, under an argon atmosphere, prior to analysis. The samples were then randomly scanned and photographed.

\subsection{X-ray Powder Diffraction}

X-ray diffraction measurements on SAP and SAP-loaded and unloaded MS were performed at $40 \mathrm{kV}, 40 \mathrm{~mA}$, with the Bruker AXS D8 Advance Geiger counter equipped with a two-dimensional (2D) gas-filled sealed multiwire detector (scattering-angle resolution of $0.02^{\circ} \mathrm{s}^{-1}$ ). Monochromatized $\mathrm{Cu} \mathrm{K} \alpha$ radiation $(\lambda=1.54 \AA)$ was used. The analyses were performed in a $5-45^{\circ} 2 \vartheta$ range, at ambient temperature. The intensity vs. scattering angle spectra was obtained after the radial average of the measured 2D isotropic diffraction patterns. Bragg peaks were detected in the wide-angle X-ray diffraction region (WAXD).

\subsection{Thermal Analysis (DSC and TGA)}

The thermal profiles of SAP and MS formulations were studied using differential scanning calorimetry (DSC823e; Mettler-Toledo, Schwerzenbach, Switzerland). Roughly $5 \mathrm{mg}$ of samples were weighted and crimp-sealed in DSC standard $40 \mu \mathrm{L}$ aluminum pans. Samples were then subjected to a $10^{\circ} \mathrm{C} / \mathrm{min}$ temperature ramp between $-20^{\circ} \mathrm{C}$ and $300^{\circ} \mathrm{C}$. The endothermic and exothermic peaks were determined using STARe software V.11.0x (Mettler Toledo, Greifensee, Switzerland).

Moreover, the temperature stability and solvent evaporation of each sample were determined using thermal gravimetric analysis (TGA; Mettler-Toledo, Schwerzenbach, Switzerland). Approximately $5 \mathrm{mg}$ of samples were placed on aluminum crucible pans. The weight losses of the samples were assessed by heating the samples from $20{ }^{\circ} \mathrm{C}$ to $400{ }^{\circ} \mathrm{C}$, with a scanning rate of $5{ }^{\circ} \mathrm{C} / \mathrm{min}$, under constant nitrogen gas. Data were analyzed using STARe software V.11.0x (Mettler Toledo, Greifensee, Switzerland) and expressed as the percentage of weight loss comparing to initial sample weight.

\subsection{Dynamic Vapor Sorption (DVS)}

The relative moisture sorption and stability of SAP and MS formulations, with respect to humidity, were analyzed by Dynamic Vapor Sorption (DVS). Aluminum sample pans were loaded with $10 \mathrm{mg}$ ca. of samples and then placed in the sample chamber of a DVS (DVS-1, Surface Measurement Systems Ltd., London, UK). Each sample was dried at $0 \%$ relative humidity (RH) before being exposed to $10 \% \mathrm{RH}$ increments for two $0-90 \% \mathrm{RH}$ cycles $\left(25^{\circ} \mathrm{C}\right)$. Equilibrium of moisture sorption was determined, at each humidity step, by a change in mass to time ratio $(\mathrm{dm} / \mathrm{dt})$ of $0.0005 \% \mathrm{~min}^{-1}$. 


\subsection{Solubility Test}

The solubility of SAP in a release medium (0.01 M PBS, $\mathrm{pH}=7.4)$ was assessed in triplicate by solvent saturation method. An excess amount of SAP was added into tubes containing $2.5 \mathrm{~mL}$ of PBS. The tubes were sonicated into a water-bath sonicator at $32 \mathrm{KHz}$ and $32{ }^{\circ} \mathrm{C}$, for $1 \mathrm{~h}$, and then stirred on a thermostated orbital shaker at $120 \mathrm{rpm}$ and $32{ }^{\circ} \mathrm{C}$, for $24 \mathrm{~h}$. The tubes were then centrifuged at $2000 \mathrm{rpm}$ for $5 \mathrm{~min}$. The supernatants were withdrawn, filtered using $0.22 \mu \mathrm{m}$ polyamide syringe filters, diluted with PBS and analyzed by UV spectroscopy.

\subsection{In Vitro Drug Release Studies}

For topical microcarriers, there are no compendial or standard release methods and apparatuses [31,32]. Therefore, in vitro release profiles of SAP from HA and HA-CL MS were evaluated with two different methodologies, under different experimental conditions.

\subsubsection{Dialysis}

SAP release profiles were primarily obtained with dialysis method. A calculated amount of each test formulation containing $\sim 10 \mathrm{mg}$ of SAP was placed into a preconditioned dialysis bag (Slide-A-Lyzer G2, 10kDa MWCO, Thermo Fisher Scientific, Rodano, Milano, Italy), and dialyzed against $300 \mathrm{~mL}$ PBS $(0.01 \mathrm{M}, \mathrm{pH}=7.4)$, a release medium already described in the literature for drug release studies of dermal carriers [31,33,34]. The whole set-up was continuously stirred at $150 \mathrm{rpm}$ and maintained at $32 \pm 1{ }^{\circ} \mathrm{C}$ to reflect the physiological skin temperature [31]. At predefined time intervals, $1 \mathrm{~mL}$ of sample was withdrawn and replaced with an equal volume of warm PBS. The released SAP was quantified by UV spectroscopy. A minimum of three replicates were performed for each test formulation.

\subsubsection{Franz Cells}

SAP release profiles from hyaluronan MS were also investigated by Franz's cells ( $25 \mathrm{~mm}$ internal diameter, PermeGear Inc., Hellertown, PA, USA). Polyamide filter membranes $0.45 \mu \mathrm{m}$ pore size (Sartorius Biolab Products, Goettingen, Germany) were hydrated by sonication in deionized water for $30 \mathrm{~min}$, and then cut and mounted between the receiver and donor compartments of the diffusion cells. The whole diffusion cells were put in a thermostatic bath, maintained at $32 \pm 1{ }^{\circ} \mathrm{C}$. Test formulations were placed in the donor compartments-in order to have $\sim 2 \mathrm{mg}$ of SAP on the surface of the membranes - which were closed using a wax foil (Parafilm M, Bemis Company Inc., Oshkosh, WI, USA) to prevent evaporation. The receiver compartments were filled with $23 \mathrm{~mL}$ PBS $(0.01 \mathrm{M}, \mathrm{pH}=7.4)$ and kept under continuous magnetic stirring at $150 \mathrm{rpm}$. At selected time points, $0.5 \mathrm{~mL}$ of samples were withdrawn from the receptor compartment and replaced with equal volumes of warm PBS. Samples were assayed for SAP content using UV spectroscopy. A minimum of three replicates was performed for each formulation. The idea was to get preliminary indications which, if positive, will be used to support a request to the ethics committee for a human skin study.

\subsection{Drug Release Data Analysis}

All the experimental release data were fitted to a series of statistical and kinetic models to evaluate formulations performances and to elucidate their drug release mechanisms, strictly related to the properties of the polymers. This detailed mathematical modeling study was carried out to develop and characterize our novel HA CL MS, in comparison to HA MS, with a systematic approach.

\subsubsection{Similarity and Difference Factors for SAP Release Profiles}

For each release method used, SAP diffusion across the membranes and SAP release profiles from HA MS and HA CL MS were statistically analyzed and compared using Fit Factors described by Moore and Flanner [35], adopted by the Food and Drug Administration guidance for dissolution 
testing in the industry [36]. Fit factors are models widely applied by researchers [37-40] to directly compare the difference between percentage drug released per unit time between a reference and a test formulation. The difference factor $\left(f_{1}\right)$ and the similarity factor $\left(f_{2}\right)$ were calculated using Equations (6) and (7), respectively

$$
\begin{gathered}
f_{1}=\left\{\left[\sum_{t=1}^{n}\left|R_{t}-T_{t}\right| / \sum_{t=1}^{n} R_{t}\right]\right\} \cdot 100 \\
f_{2}=50 \cdot \log \left\{\left[1+(1 / n) \sum\left(R_{t}-T_{t}\right)^{2}\right]^{-0.5} \cdot 100\right\}
\end{gathered}
$$

where $R_{t}$ and $T_{t}$ are percentages of drug released at a certain time point $(t)$ from the reference and the test formulation, respectively; $n$ is the number of dissolution sampling times. The difference factor $\left(f_{1}\right)$ calculates the percent difference between the reference and the test curves at each time point thus measuring the relative error between the two curves. The similarity factor $\left(f_{2}\right)$ is a logarithmic reciprocal square root transformation of the sum of squared error and is a measurement of the similarity in percentage released between curves. For data analysis, arbitrary descriptors of difference and similarity need to be chosen: curves were considered different with $f_{1} \geq 10$ and $f_{2} \leq 50$.

\subsubsection{Analysis of SAP Release Kinetics Using Mathematical Models}

SAP release data acquired for HA and HA-CL MS were plotted into four mathematical models corresponding to the known release mechanisms. The linearized form of each function was evaluated using the R2 regression analysis, in order to understand which was the best-fit mathematical model and, therefore, the kinetic process controlling SAP release from hyaluronan MS.

The first model used, called Zero-release kinetic, describes a release mechanism whose rate is independent of the active ingredient concentration, but it is time-dependent [41]. It is described by Equation (8)

$$
\frac{Q_{t}}{Q_{\infty}}=K t+Q_{0}
$$

where $Q_{t} / Q_{\infty}$ is the ratio between the cumulative percentage of drug released at time $t$ and at infinite time, $k$ is the zero-order release constant, $t$ is the time, and $Q_{0}$ is the initial quantity of drug in solution due to an immediate releasing process (most times $Q_{0}=0$ ).

On the contrary, the First order model delineates a process where the release rate is concentration dependent [41]. It is represented by Equation (9)

$$
\log \log \frac{Q_{t}}{Q_{\infty}}=\log \log Q_{0}-k t / 2.303
$$

where $Q_{t} / Q_{\infty}$ is the ratio between the cumulative percentage of drug released at time $t$ and at infinite time, $k$ is the first-order release constant, $t$ is the time, and $Q_{0}$ is the initial amount of drug in solution.

Also, the Higuchi model was applied [42]. It describes drug release from a matrix system whose swelling is negligible [41,43]. Therefore, the release profile is governed by the properties of the polymeric matrix and by drug solubility, and it is described by the following equation

$$
\frac{Q_{t}}{Q_{\infty}}=k_{H} \sqrt{t}+Q_{0}
$$

where $Q_{t} / Q_{\infty}$ is the ratio between the cumulative percentage of drug released at time $t$ and at infinite time, $k$ is the Higuchi release rate constant, $t$ is the time, and $Q_{0}$ is the initial quantity of drug in solution due to an immediate releasing process (most times $Q_{0}=0$ ).

Finally, the release data were fitted to the Korsmeyer-Peppas model, which describes the drug release from swelling-controlled systems [41,43-46]. In these polymeric systems, both diffusion and dissolution occur together, and they are quite indistinguishable. Korsmeyer-Peppas proposed the following semi-empirical equation 


$$
\frac{Q_{t}}{Q_{\infty}}=k t^{n}+Q_{0}
$$

where $Q_{t} / Q_{\infty}$ is the ratio between the cumulative percentage of drug released at time $t$ and at infinite time, $k$ is a kinetic constant related to the structural and geometric properties of the system, $t$ is the time, $n$ is the release exponent (connected to geometric form), and $Q_{0}$ is the initial amount of drug in solution. In this model, the $n$ value characterizes the release mechanism: Fickian diffusion, i.e., drug diffusive process, is prevalent for $n \approx 0.43$; Case-II transport, i.e., polymer dissolution process, for $n \approx 0.89$; super Case-II transport for $n>0.89$; anomalous behavior, i.e., a superposition of diffusion and dissolution, for $0.43<n<0.89$.

\subsection{Statistical Analysis}

Data are presented as mean \pm SD of three independent experiments $(n=3)$. Statistical analysis was performed using GraphPad Prism software version 7.0b (GraphPad, San Diego, CA, USA). The tests used were one-way (characterization of hyaluronan solutions) or two-way (characterization of MS during the pre-formulation study) analysis of variance (ANOVA), followed by Tukey post hoc analysis for multiple comparisons. Differences between results were considered statistically significant at $p<0.05$.

\section{Results and Discussion}

\subsection{Pre-Formulation Study: Evaluation and Optimization of Microspheres}

The present work describes the production and characterization of MS using two different hyaluronans: HA-CL (test polymer) and native HA (reference polymer already employed to formulate microspheres) $[10,11]$. The aim was to understand if the novel HA-CL could be a promising candidate to obtain MS intended for skin application. It is well known that particles features are affected by the properties of the starting polymer solutions and by factors related to the production method $[8,23,47]$. In this document, we correlated MS properties to the $\mathrm{pH}$ and the rheological behavior of HA aqueous phases, and to the emulsification time. This systematic approach was used in order to facilitate the development of our novel formulations, considering that this was the first study to investigate the novel HA-CL as microcarrier.

All the hyaluronan solutions were characterized by a shear-thinning (Figure 1) and viscoelastic behavior. However, statistical analysis demonstrated that each solution was significantly different $(p<0.05)$ from the others in terms of $\mathrm{pH}$, zero-shear-rate viscosity $\left(\eta_{0}\right)$, elastic modulus at $1 \mathrm{~Hz}\left(G_{1 H z}^{\prime}\right)$, and crossover frequency (Cf). Indeed, HA type and SAP presence affected the values of $\mathrm{pH}, \eta_{0}, G^{\prime}{ }_{1 \mathrm{~Hz}}$, and Cf (Table 1).

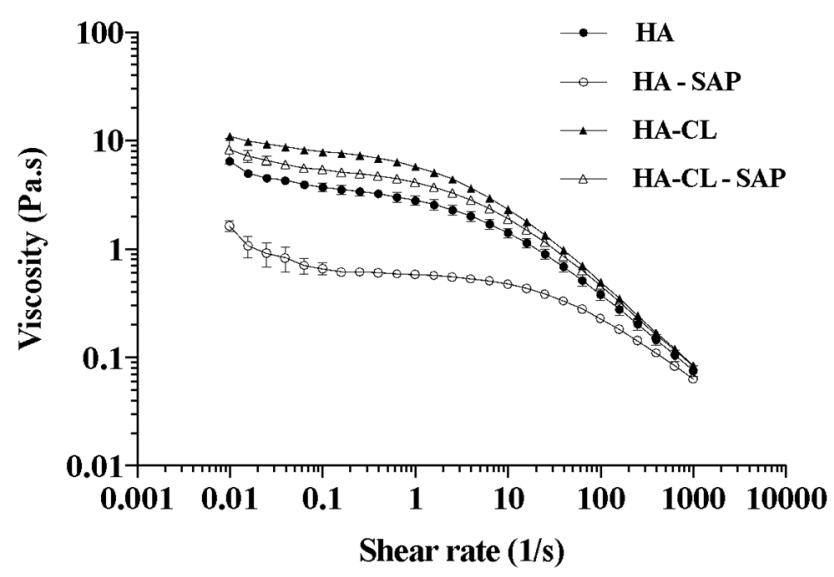

Figure 1. Shear-thinning behavior of hyaluronan solutions: viscosity as a function of shear rate $(n=3, \pm \mathrm{SD})$. 
Table 1. Main properties of HA solutions: $\mathrm{pH}, \eta_{0}, \mathrm{G}_{1 H z}^{\prime}, C_{f}(n=3, \pm \mathrm{SD})$.

\begin{tabular}{ccccc}
\hline Solution & $\mathbf{p H}$ & $\boldsymbol{\eta}_{\boldsymbol{0}}$ (Pa.s) & $\boldsymbol{G}^{\prime}{ }_{\mathbf{1 H z}} \mathbf{( P a )}$ & $\boldsymbol{C}_{f} \mathbf{( H z )}$ \\
\hline HA & $6.8 \pm 0.1$ & $4.2 \pm 0.2$ & $5.5 \pm 0.7$ & $6.2 \pm 1.8$ \\
HA-SAP & $8.9 \pm 0.1$ & $0.7 \pm 0.0$ & $0.8 \pm 0.0$ & $15.9 \pm 0.4$ \\
HA-CL & $7.2 \pm 0.0$ & $9.1 \pm 0.3$ & $13.2 \pm 0.6$ & $1.8 \pm 0.0$ \\
HA-CL-SAP & $8.1 \pm 0.1$ & $6.3 \pm 0.5$ & $9.2 \pm 0.4$ & $3.1 \pm 0.1$ \\
\hline
\end{tabular}

As regarding the impact of polymer type, Table 1 shows implemented mechanical properties for HA-CL hydrogel with respect to HA hydrogel (i.e., higher $\eta_{0}$ and $G^{\prime}{ }_{1 H z}$, lower Cf). Considering, for example, simple polymeric solutions, $\eta_{0}, G^{\prime}{ }_{1 \mathrm{~Hz}}$ and $\mathrm{Cf}$ were respectively $9.1 \pm 0.3 \mathrm{~Pa} . \mathrm{s}, 13.2 \pm 0.6 \mathrm{~Pa}$ and $1.8 \pm 0.0 \mathrm{~Hz}$ for HA-CL, and 4.2 $\pm 0.2 \mathrm{~Pa} . \mathrm{s}, 5.5 \pm 0.7 \mathrm{~Pa}$ and $6.2 \pm 1.8 \mathrm{~Hz}$ for HA. This could be ascribed to the different molecular weight of the two polymers (1.2 MDa for native HA, 3.0 MDa for HA-CL), and to the crosslinking of the urea derivative. Indeed, it is well known that the viscosity and the viscoelasticity of hyaluronan solutions increase with increasing polymer molecular weight [48] and crosslinking [13,49]. For the shorter emulsification times investigated (10 and $30 \mathrm{~min})$, the rheological behavior of HA and HA-CL solutions seemed to be reflected in the mean size of the resulting particles. Certainly, Dv50 and D[4,3] values were significantly higher $(p<0.05)$ for HA-CL MS with respect to HA MS produced after the same mixing time (Table 2). After $10 \mathrm{~min}$ of emulsification, Dv50 and $\mathrm{D}[4,3]$ were respectively $290.0 \pm 32.5 \mu \mathrm{m}$ and $311.0 \pm 32.5 \mu \mathrm{m}$ for HA-CL MS, and $117.7 \pm 20.0 \mu \mathrm{m}$ and $246.0 \pm 53.6 \mu \mathrm{m}$ for HA MS. Moreover, after $30 \mathrm{~min}$ of emulsification, Dv50 and D[4,3] were specifically $181.5 \pm 3.8 \mu \mathrm{m}$ and $208.7 \pm 6.7 \mu \mathrm{m}$ for HA-CL MS, and $113.7 \pm 19.6 \mu \mathrm{m}$ and $154.7 \pm 27.5 \mu \mathrm{m}$ for HA MS. Similar findings have already been reported in the literature: bigger particles are generally produced by larger droplets of the precursory $w / 0$ emulsion [8], formed by increasing the solution viscosity [50].

Table 2. Effect of emulsification time, polymer type, and SAP presence on MS properties $(n=3, \pm$ SD).

\begin{tabular}{|c|c|c|c|c|c|c|}
\hline MS Formulation & $\operatorname{Dv} 50(\mu \mathrm{m})$ & $\mathrm{D}[4,3](\mu \mathrm{m})$ & Span & $Y(\%)$ & DL(\%) & $\mathrm{EE}(\%)$ \\
\hline \multicolumn{7}{|l|}{$10 \min$} \\
\hline HA & $117.7 \pm 20.0$ & $246.0 \pm 53.6$ & $4.2 \pm 0.4$ & $68.6 \pm 1.6$ & - & - \\
\hline HA-SAP & $71.7 \pm 4.2$ & $121.0 \pm 13.4$ & $4.3 \pm 0.1$ & $75.2 \pm 4.4$ & $39.2 \pm 0.4$ & $59.0 \pm 4.0$ \\
\hline HA-CL & $290.0 \pm 32.5$ & $311.0 \pm 32.5$ & $1.5 \pm 0.2$ & $56.7 \pm 5.4$ & - & - \\
\hline HA-CL-SAP & $245.5 \pm 27.6$ & $300.5 \pm 24.7$ & $2.4 \pm 0.5$ & $70.6 \pm 1.1$ & $32.5 \pm 1.4$ & $65.3 \pm 3.5$ \\
\hline \multicolumn{7}{|l|}{$30 \mathrm{~min}$} \\
\hline HA & $113.7 \pm 19.6$ & $154.7 \pm 27.5$ & $2.9 \pm 0.1$ & $79.4 \pm 2.9$ & - & - \\
\hline HA-SAP & $54.6 \pm 3.0$ & $63.2 \pm 2.6$ & $2.0 \pm 0.1$ & $81.5 \pm 1.4$ & $39.3 \pm 1.0$ & $64.1 \pm 2.9$ \\
\hline HA-CL & $181.5 \pm 3.8$ & $208.7 \pm 6.7$ & $2.5 \pm 0.1$ & $76.7 \pm 1.3$ & - & - \\
\hline HA-CL-SAP & $117.0 \pm 4.2$ & $135.0 \pm 3.5$ & $2.3 \pm 0.0$ & $78.2 \pm 3.3$ & $32.1 \pm 1.0$ & $68.9 \pm 1.0$ \\
\hline \multicolumn{7}{|l|}{$60 \mathrm{~min}$} \\
\hline HA & $2.5 \pm 0.1$ & $6.3 \pm 0.5$ & $2.9 \pm 0.2$ & $88.4 \pm 1.7$ & - & - \\
\hline HA-SAP & $2.5 \pm 0.1$ & $3.1 \pm 0.2$ & $2.2 \pm 0.0$ & $84.2 \pm 2.3$ & $41.3 \pm 1.6$ & $69.7 \pm 4.6$ \\
\hline HA-CL & $13.0 \pm 0.7$ & $21.6 \pm 4.0$ & $2.5 \pm 0.3$ & $85.8 \pm 4.4$ & - & - \\
\hline HA-CL-SAP & $9.9 \pm 0.8$ & $15.2 \pm 4.0$ & $2.6 \pm 0.2$ & $85.0 \pm 4.8$ & $33.6 \pm 2.3$ & $78.8 \pm 2.6$ \\
\hline
\end{tabular}

Concerning the influence of SAP on the properties of HA and HA-CL solutions, it increased the $\mathrm{pH}$, thus causing (as expected [51,52]) a statistically significant $(p<0.05)$ decrease of $\eta_{0}$ and $G^{\prime}{ }_{1 \mathrm{~Hz}}$, and an increase of $\mathrm{Cf}$ (Table 1). In fact, the $\mathrm{pH}, \eta_{0}, \mathrm{G}_{1 \mathrm{~Hz}}$ and $\mathrm{Cf}$ of HA hydrogel, which were respectively $6.8 \pm 0.1,4.2 \pm 0.2$ Pa.s, $5.5 \pm 0.7 \mathrm{~Pa}$ and $6.2 \pm 1.8 \mathrm{~Hz}$, changed to $8.9 \pm 0.1,0.7 \pm 0.0$ Pa.s, $0.8 \pm 0.0 \mathrm{~Pa}$ and $15.9 \pm 0.4 \mathrm{~Hz}$ in presence of SAP. A similar trend was observed also for HA-CL solutions: without SAP, the $\mathrm{pH}, \eta_{0}, \mathrm{G}_{1 \mathrm{~Hz}}^{\prime}$ and Cf were respectively $7.2 \pm 0.0,9.1 \pm 0.3 \mathrm{~Pa} . \mathrm{s}, 13.2 \pm 0.6 \mathrm{~Pa}$ and $1.8 \pm 0.0 \mathrm{~Hz}$; in presence of SAP, these values changed to $8.1 \pm 0.1,6.3 \pm 0.5 \mathrm{~Pa} . \mathrm{s}, 9.2 \pm 0.4 \mathrm{~Pa}$ and $3.1 \pm 0.1 \mathrm{~Hz}$. Also, in this case, the rheology of the initial solutions appeared correlated to the dimensional properties of the particles. Indeed, for the same HA type and emulsification time (10 or $30 \mathrm{~min})$, SAP-loaded MS were 
smaller than unloaded MS (Table 2), as highlighted by statistical analysis $(p<0.05)$. For example, after a 10 min' emulsification, Dv50 and D[4,3] of HA MS respectively decreased from $117.7 \pm 20.0 \mu \mathrm{m}$ and $246.0 \pm 53.6 \mu \mathrm{m}$ to $71.7 \pm 4.2 \mu \mathrm{m}$ and $121.0 \pm 13.4 \mu \mathrm{m}$ in presence of SAP. Similarly, Dv50 and D[4,3] of HA-CL MS respectively decreased from $290.0 \pm 32.5 \mu \mathrm{m}$ and $311.0 \pm 32.5 \mu \mathrm{m}$ to $245.5 \pm 27.6 \mu \mathrm{m}$ and $300.5 \pm 24.7 \mu \mathrm{m}$ in presence of SAP. In the same way, after $30 \mathrm{~min}$ of emulsification, HA and HA-CL MS mean size decreased when encapsulating SAP, as reported in Table 2.

In summary, the effect of HA type and SAP presence on MS diameter appeared statistically significant $(p<0.05)$ in the case of 10 and $30 \mathrm{~min}$ of emulsification. For MS produced after $60 \mathrm{~min}$ of mixing, this effect was negligible. Indeed, particles were all comparable in term of size, regardless of polymer type and SAP loading, with Dv50 ranging from $2.5 \pm 0.1$ to $13.0 \pm 0.7 \mu \mathrm{m}$, and D[4,3] ranging from $3.1 \pm 0.2$ to $21.6 \pm 4.0 \mu \mathrm{m}$ (Table 2). Therefore, after $60 \mathrm{~min}$, the side effects due to the differences between hyaluronan solutions were leveled because of a more significative emulsification. Consequently, MS mean diameter and size distribution seemed to be affected not only by the rheology of the starting solution but also by the emulsification time. For each MS formulation, particle diameter was found to be inversely proportional to the emulsification time in the range 10-60 min (Table 2). This correlation was statistically significant $(p<0.05)$, and it was in agreement with previously reported results [47]. Indeed, the higher is the mixing time the smaller are the droplets produced during the emulsification, and, consequently, the final particles. On the contrary, the shorter is the emulsification time, the less fine is the w/o emulsion, and this normally determines the aggregation of aqueous droplets. As already observed [8], also in our study bigger and less uniform-sized MS, with a lower yield, were produced by droplets agglomeration -supposed to occur especially for 10 min' emulsification (Table 2). This drawback could be probably due to the bioadhesivity of the polymers which, when less dispersed, adhere more to the homogenizer workhead. However, by increasing the emulsification time from 10 to $60 \mathrm{~min}$, MS mean size significantly decreased, while particle recovery $(\mathrm{Y} \%)$ and encapsulation efficiency $(\mathrm{EE} \%)$ significantly increased $(p<0.05)$ (Table 2$)$. For example, SAP-loaded HA MS could be considered: after 10 min of emulsification, Dv50, D[4,3], Span, Y\% and $\mathrm{EE} \%$ values were respectively $71.7 \pm 4.2 \mu \mathrm{m}, 121.0 \pm 13.4 \mu \mathrm{m}, 4.3 \pm 0.1,75.2 \pm 4.4 \%$ and $59.0 \pm 4.0 \%$. After $60 \mathrm{~min}$ of emulsification, these values became respectively $2.5 \pm 0.1 \mu \mathrm{m}, 3.1 \pm 0.2 \mu \mathrm{m}, 2.2 \pm 0.0$, $84.2 \pm 2.3 \%$ and $69.7 \pm 4.6 \%$. Considering the parallel increment of particles $\mathrm{Y} \%$ and $\mathrm{EE} \%$, the drug loading (DL\%) remained almost constant whatever the emulsification time (around $40 \%$ for SAP-loaded HA MS and 33\% for SAP-loaded HA-CL MS) (Table 2).

Taking into account the results of this pre-formulation study, the emulsification time of $60 \mathrm{~min}$ was chosen as the standard condition to produce optimized MS. Indeed, all the MS formulations produced after 60 min of emulsification were characterized by the highest $Y \%$, ranging from $84.2 \pm 2.3$ to $88.4 \pm 1.7 \%$ (comparable values). The EE\% and DL\% were satisfying, even if statistically different $(p<0.05)$ for HA and HA-CL formulations: respectively $69.7 \pm 4.6 \%$ and $41.3 \pm 1.6 \%$ for HA-SAP MS, and $78.8 \pm 2.6 \%$ and $33.6 \pm 2.3 \%$ for HA-CL-SAP MS (Table 2). Particle Dv50 ranging from $2.5 \pm 0.1$ to $13.0 \pm 0.7 \mu \mathrm{m}$, and $\mathrm{D}[4,3]$ ranging from $3.1 \pm 0.2$ to $21.6 \pm 4.0 \mu \mathrm{m}$ (Table 2) were suitable for dermal target $[53,54]$. Indeed, to avoid palpable microspheres during application, mean size should be lower than $50 \mu \mathrm{m}$ [55]: this is essential both in the cosmetic and pharmaceutic field, as it determines the cosmetic elegance of a product [55] and the adherence to a therapy [56]. A statistical comparison revealed no significant difference between the mean size of optimized MS ( $p>0.05)$. Moreover, all the optimized formulations showed almost unimodal size distributions (Figure 2), with Span values lower than 3 (Table 2).

Optimized MS underwent a deeper physical-chemical characterization: analysis of morphology, physical and molecular state, thermal properties, relative moisture sorption, and stability, in vitro release properties, and kinetic mechanisms. 


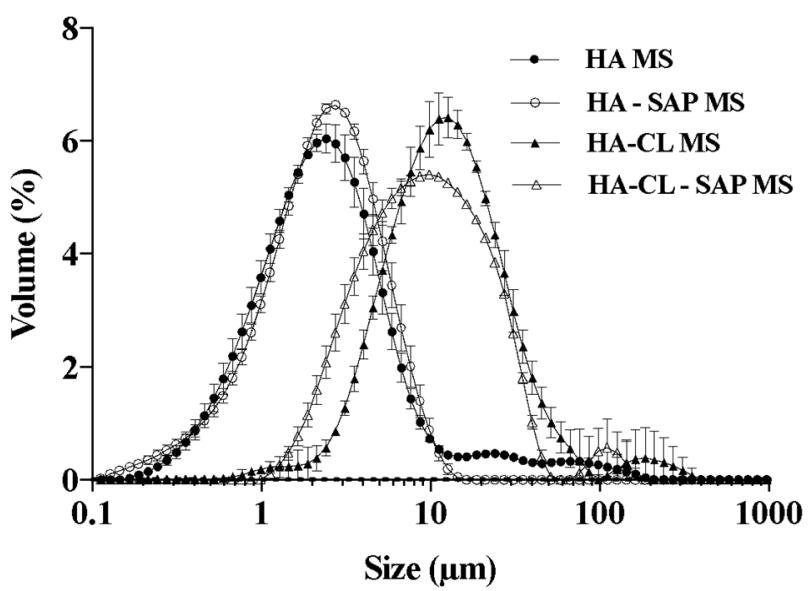

Figure 2. Particle size distribution of hyaluronan MS produced after $60 \mathrm{~min}$ of emulsification $(n=3, \pm \mathrm{SD})$.

\subsection{Characterization of Optimized Microspheres}

\subsubsection{SEM Morphological Analysis}

As regarding particle morphology, all hyaluronan MS encapsulating or not SAP showed a spherical shape. However, polymer typology (HA or HA-CL) influenced MS surface properties. Indeed, SAP-loaded and unloaded HA MS exhibited a regular and smooth surface, while SAP-loaded and unloaded HA-CL MS were characterized by an irregular and rough surface (Figure 3).
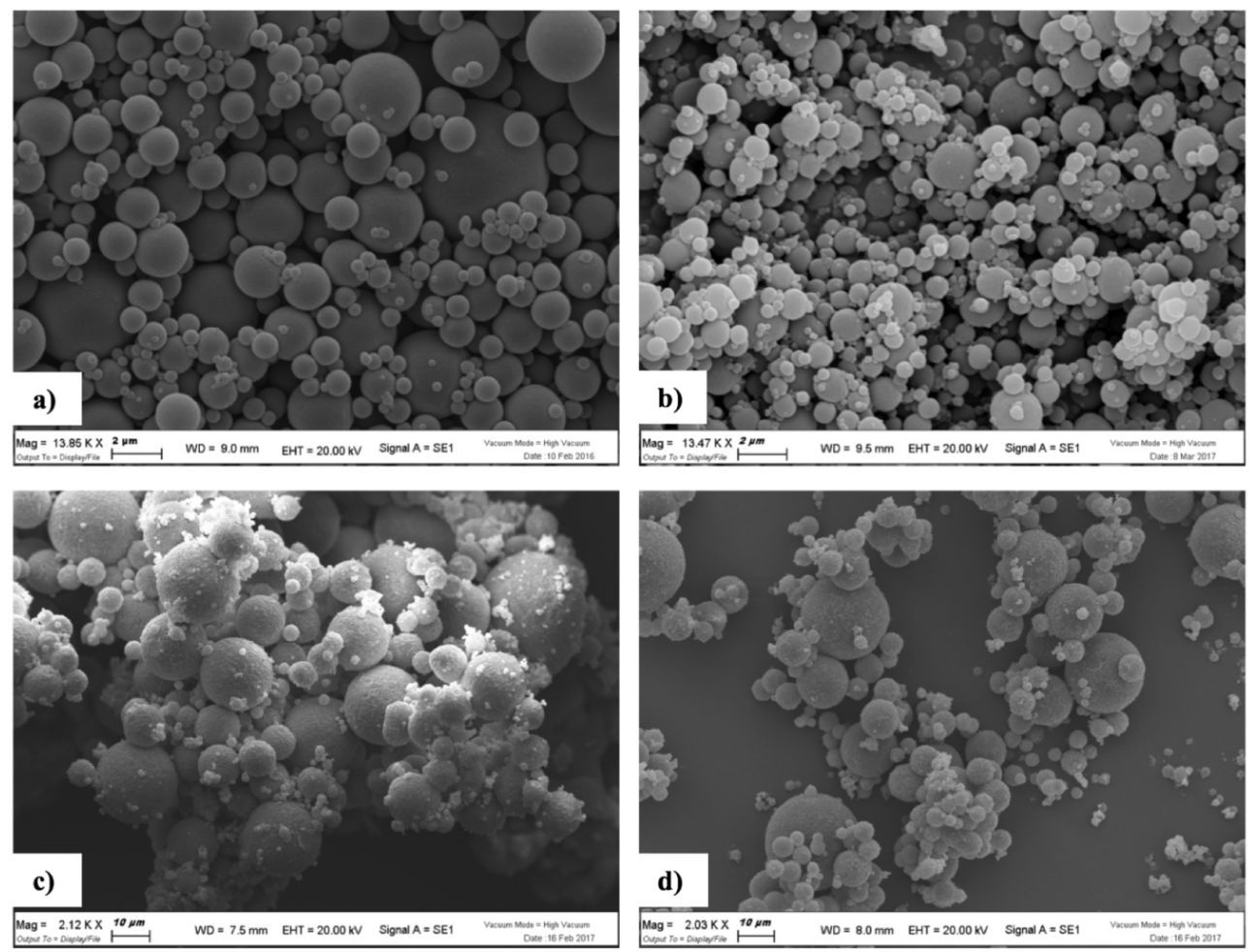

Figure 3. SEM micrographs of hyaluronan MS produced after $60 \mathrm{~min}$ of emulsification: HA (a), HA-SAP (b), HA-CL (c), HA-CL-SAP (d).

\subsubsection{X-ray Diffraction}

Wide angle X-ray diffractometry was performed to investigate the molecular states of MS formulations in comparison to SAP [57]. The diffraction patterns are reported in Figure 4. The WAXD pattern of unloaded HA and HA-CL MS exhibited humps typical of disordered structures, i.e., 
amorphous materials. SAP pattern was characterized by four low intense and broad peaks emerging from a hump at $2 \vartheta=7.30,20.00,27.32$, and $33.12^{\circ}$, which can be ascribed to small traits of crystallinity. Indeed, the diffraction intensity is defined by the crystal structure: the higher is the crystallinity degree, the higher is the intensity of the peaks [57]. The diffraction patterns of SAP-loaded MS showed both the main signals of the drug and of the carrier, indicating the permanence of SAP crystalline traits into the amorphous matrixes of HA and HA-CL. However, thermal analyses and DVS study provided evidence and confirmation that the crystallinity of SAP loaded MS was so low to be negligible.

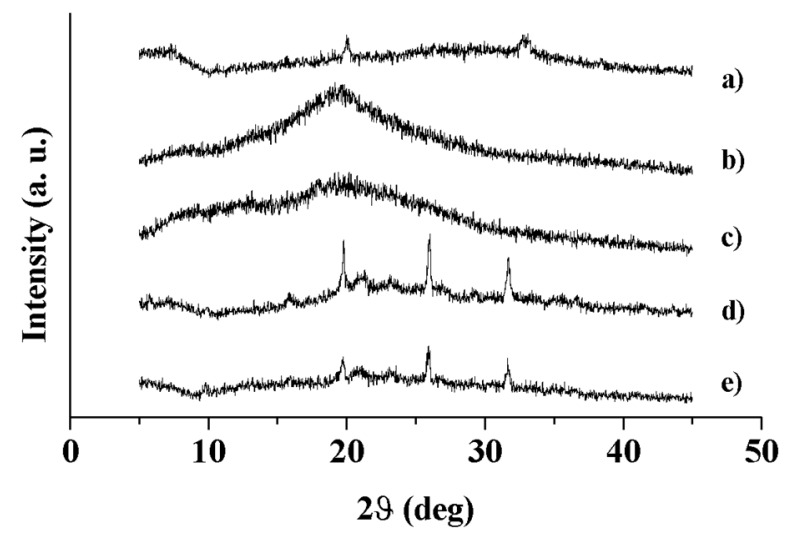

Figure 4. X-ray diffraction patterns of: SAP (a), HA MS (b), HA-CL MS (c), HA-SAP MS (d), HA-CL-SAP MS (e).

\subsubsection{Thermal Analysis (DSC and TGA)}

DSC and TGA were used to characterize the thermal behavior and stability of the drug and the formulations, providing information on their hydration properties and their physical state [58,59]. Figure 5 shows the DSC thermal profiles of SAP and MS formulations. SAP thermogram (a) was characterized by broad endothermic peaks around $67^{\circ} \mathrm{C}$ and $100{ }^{\circ} \mathrm{C}$, which could be associated with the loss of moisture after the initial drying procedure, and by a sharp exothermic peak at $233{ }^{\circ} \mathrm{C}$, due to the melting point with thermal decomposition (as reported in the literature for similar ascorbic acid derivatives [60]). DSC thermal profile of HA MS (b) presented a wide endothermic peak, suggesting a dehydration process around $103{ }^{\circ} \mathrm{C}$, and a broad exothermic peak at $240{ }^{\circ} \mathrm{C}$ ascribable to the polymer thermal decomposition and the formation of a carbonized residue. These results were in good agreement with previous observations for native HA $[49,61,62]$. DSC trace of HA-CL MS (c) exhibited a broad endothermic peak at $200^{\circ} \mathrm{C}$, which could be attributed to pentylene glycol evaporation (boiling range $198-200{ }^{\circ} \mathrm{C}$ ). This was confirmed by pentylene glycol DSC thermal profile (trace not shown). Moreover, HA-CL MS curve showed a wide exothermic peak, due to polymer thermal degradation, at $250{ }^{\circ} \mathrm{C}$ (shifted with respect to HA MS, indicating an altered structure due to crosslinking [61]). The thermograms of HA - SAP MS (d) and HA-CL-SAP MS (e) showed the same profile of the corresponding unloaded MS (DSC traces $b$ and $d$, respectively), but the peaks shifted to lower temperatures (about $10-15^{\circ} \mathrm{C}$ of shift). This evidence, in addition to the reduced intensity of the exothermic peak, suggested an altered microstructure of the polymer matrix due to SAP presence (probable molecular dispersion of SAP inside the microspheres [24]) and the superposition of SAP and hyaluronan thermal degradation phenomena. 


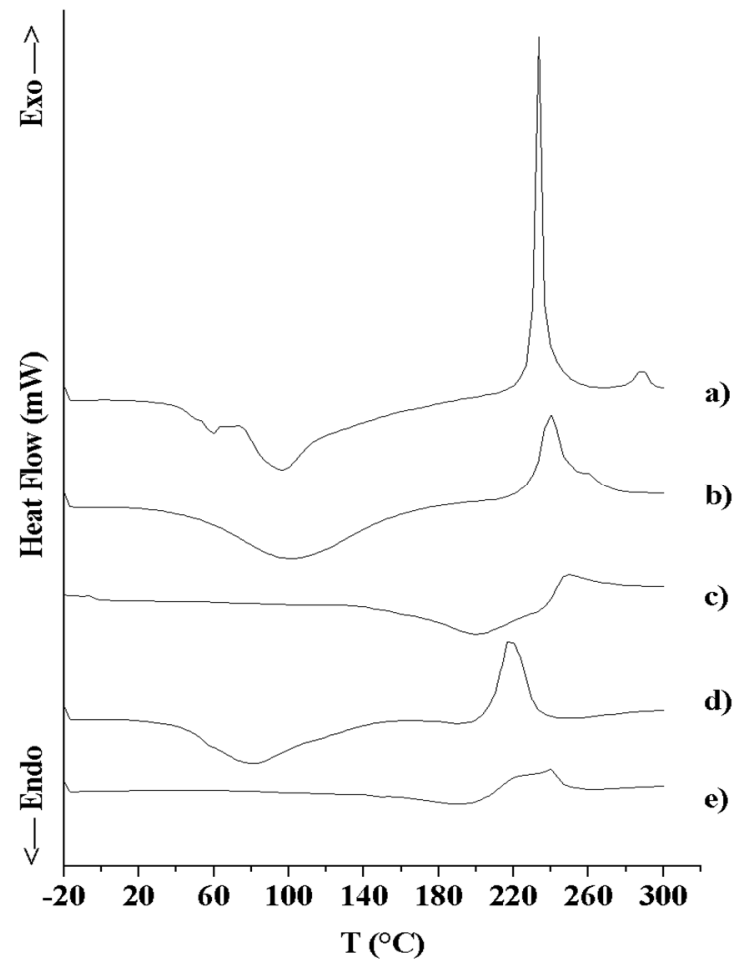

Figure 5. DSC thermal profiles of: SAP (a), HA MS (b), HA-CL MS (c), HA-SAP MS (d), HA-CL-SAP MS (e).

TGA thermal profiles of SAP and MS formulations are reported in Figure 6. SAP thermogram (a) showed the first region of weight loss $\left(9.6 \% \mathrm{w} / \mathrm{w}\right.$ ) between ambient temperature and $223^{\circ} \mathrm{C}$ (moisture loss), and a second region (20.5\% $w / w)$ from 223 to $400{ }^{\circ} \mathrm{C}$ (melting with decomposition and release of volatile degradation products). TGA curve of HA MS (b) consisted of three distinct degradation stages: the first one ( $20-223^{\circ} \mathrm{C}$, showing $6.2 \% w / w$ of weight loss, due to water evaporation); the second $\left(223-269^{\circ} \mathrm{C}\right)$ and the third stages $\left(269-400{ }^{\circ} \mathrm{C}\right)$, typical of a two-stages polysaccharide degradation. In the second stage, the $37.3 \% w / w$ of weight was lost due to a partial breakage of the molecular structure. Residues of hyaluronan were then degraded in the third stage, characterized by the $12.0 \%$ $w / w$ of weight loss. Similar findings have already been described in the literature for native HA [63-65]. A comparable TGA profile characterized HA-SAP MS (d), with $10.8 \% w / w$ of weight loss in the first region $\left(20-208{ }^{\circ} \mathrm{C}\right), 26.2 \% w / w$ in the second $\left(208-258{ }^{\circ} \mathrm{C}\right)$, and $12.0 \% w / w$ in the third $\left(258-400{ }^{\circ} \mathrm{C}\right)$. For HA-SAP MS the decomposition of polymer and drug seemed to occur at once. TGA thermograms of HA-CL MS (c) and HA-CL-SAP MS (e) presented the two-stages polysaccharide degradation observed also for HA MS formulations ( $b$ and d), with an additive stage for pentylene glycol evaporation and more stages for water loss. The more gradual moisture evaporation was due to the water-binding action of pentylene glycol, humectant contained in HA-CL matrix. In detail, TGA trace of HA-CL MS (c) exhibited the following weight loss regions: three stages for water and then pentylene glycol evaporation $\left(20-97{ }^{\circ} \mathrm{C}, 97-158^{\circ} \mathrm{C}, 158-223{ }^{\circ} \mathrm{C}\right.$-total weight loss: $\left.26.2 \% w / w\right)$, and two stages for HA degradation $\left(223-265{ }^{\circ} \mathrm{C}, 223-400{ }^{\circ} \mathrm{C}\right.$-total weight loss: $\left.29.5 \% w / w\right)$. TGA thermal profile of HA-CL-SAP MS (e) was characterized by two regions for moisture and then pentylene glycol loss $\left(20-154{ }^{\circ} \mathrm{C}, 154-212{ }^{\circ} \mathrm{C}\right.$, a total weight loss of $\left.21.5 \% w / w\right)$, and two regions for HA-CL and SAP decomposition $\left(212-254{ }^{\circ} \mathrm{C}, 254-400{ }^{\circ} \mathrm{C}\right.$, a total weight loss of $\left.30.3 \% w / w\right)$. 


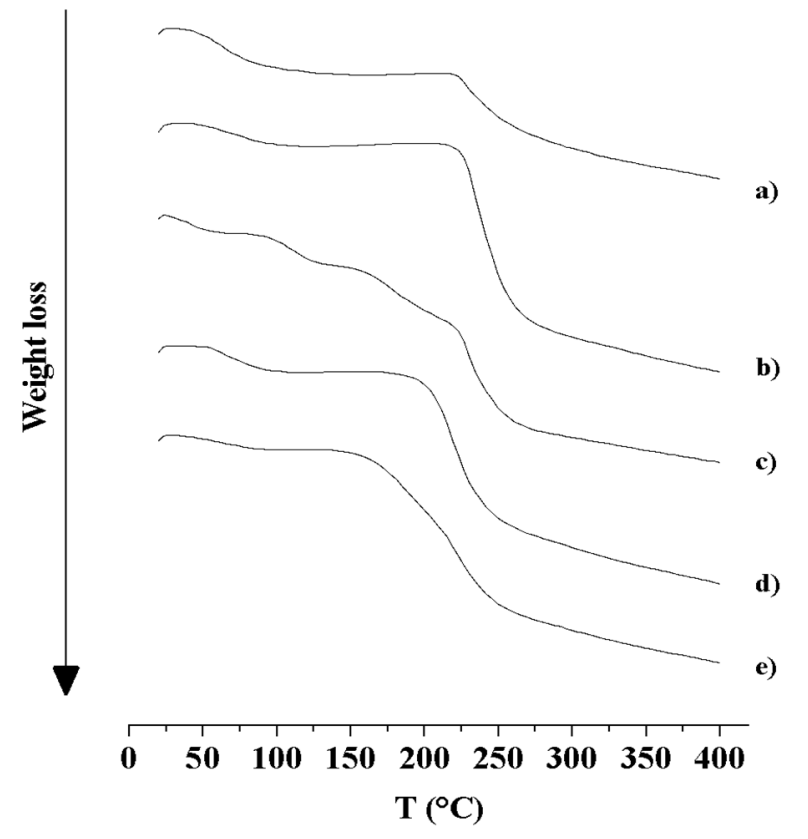

Figure 6. TGA thermograms of: SAP (a), HA MS (b), HA-CL MS (c), HA-SAP MS (d), HA-CL-SAP MS (e).

\subsubsection{Dynamic Vapor Sorption (DVS)}

It is well known that HA is a highly hygroscopic macromolecule, therefore by nature susceptible to moisture sorption and elevated relative humidity (RH) $[6,66]$. To further characterize hyaluronan MS, and evaluate the effect of SAP encapsulation, the drug, and the formulations were subjected to two $0-90 \%$ RH cycles using a DVS. The isotherms of water sorption and desorption for the first humidity ramp (cycle 1) are shown in Figure 7 as a function of the $\mathrm{RH} \%$. Following the sorption data of SAP (panel (a)), there was a linear increase of water content starting from the dry powder up to an $\mathrm{RH}$ of $40 \%$, where the moisture uptake was $6.6 \%$. A steeper increase of water sorption $(+9.6 \%)$ was observed in the RH range $40-50 \%$. The final total humidity absorbed by SAP was $27.8 \%$. The SAP desorption curve had a very different profile from the SAP sorption curve. A pronounced hysteresis was observed, and at the end of the desorption process, the final retained moisture was $15.4 \%$. On the one hand, this suggested that SAP was not reversible in terms of humidity sorption/desorption, and that water molecules were not easily detached from it, perhaps because of their condensation among the hydrophobic skeleton of the drug. On the other hand, MS formulations (panels (b) and (c)) showed, as previously observed for native HA $[67,68]$, similar trends for their sorption and desorption ramps, and high water-binding capacity due to $\mathrm{H}$-bonds and electrostatic interaction with hyaluronan hydroxyl and carboxylic groups, respectively. Two-stages moisture sorption processes occurred for hyaluronan MS formulations, and this was in agreement with data already reported in the literature for native HA $[67,68]$. Indeed, in response to $\mathrm{RH}$ increment from 0 to $60 \%$, water uptake slowly increased up to $20.9 \%$ for HA MS, $14.2 \%$ for HA-SAP MS, $16.4 \%$ for HA-CL MS, $23.0 \%$ for HA-CL-SAP MS (changes in mass similar to that of SAP $(+17.8 \%$ ) at $60 \% \mathrm{RH})$. However, the final water retention at the end of the sorption process was higher for MS formulations with respect to SAP, as moisture uptake was markedly enhanced for all the formulations in the $\mathrm{RH}$ range $60-90 \%$. At $90 \% \mathrm{RH}$, the water content was $48.5 \%$ for HA MS, $41.9 \%$ for HA-SAP MS, 73.8\% for HA-CL MS, 78.4\% for HA-CL-SAP MS. The higher moisture sorptions observed for HA-CL formulations compared to HA formulations were most likely due to the water-binding ability of urea and pentylene glycol. All the MS formulations displayed hysteresis phenomena: for the same $\mathrm{RH}$ value, during the desorption process, samples were characterized by a higher moisture level than during the sorption procedure. However, the hysteresis was reduced with respect to SAP, as well as the final moisture level at the end of the desorption process $(0 \% \mathrm{RH})$, which was $0.8 \%$ for HA MS, $4.9 \%$ for HA-SAP MS, $7.8 \%$ for HA-CL MS, $8.7 \%$ for 
HA-CL-SAP MS. Therefore, the encapsulation of SAP into hyaluronan MS produced formulations more reversible in terms of moisture sorption/desorption compared to the pure drug, even if more susceptible to high $\mathrm{RH} \%$.
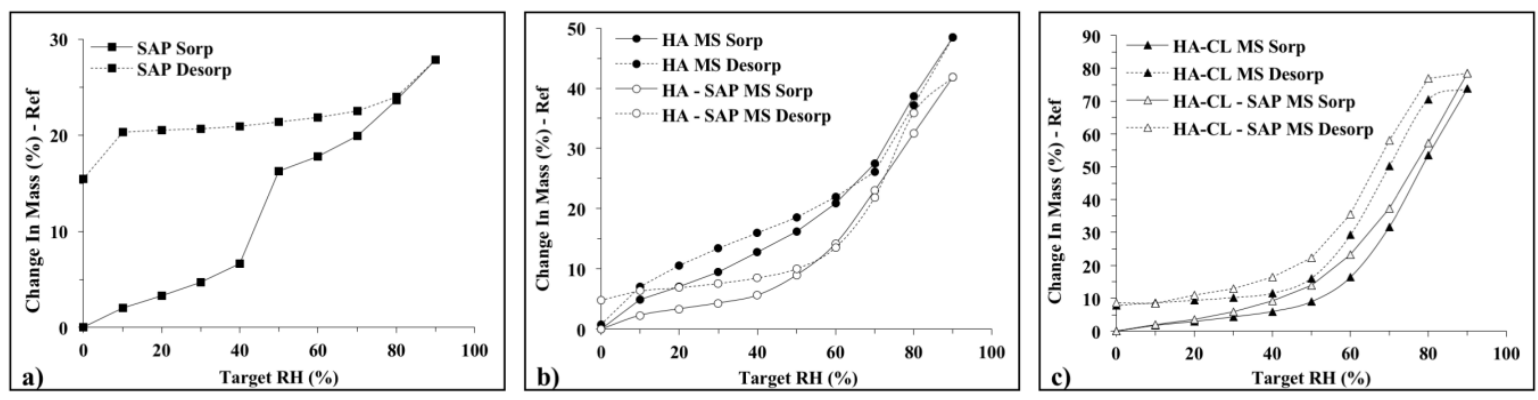

Figure 7. DVS isotherms of the first cycle sorption-desorption for: SAP (a), HA MS and HA-SAP MS (b), HA-CL MS and HA-CL-SAP MS (c).

\subsubsection{SAP Solubility}

The solubility of SAP in PBS $(0.01 \mathrm{M}, \mathrm{pH}=7.4)$ at $32{ }^{\circ} \mathrm{C}$ was $425.0 \pm 0.9 \mathrm{mg} / \mathrm{mL}$. This result displayed that sink conditions were guaranteed during the in vitro drug release studies, as SAP concentration, in the case of complete release, could reach values of $0.033 \mathrm{mg} / \mathrm{mL}$ in the dialysis tests, and $0.087 \mathrm{mg} / \mathrm{mL}$ in the Franz diffusion cell tests.

\subsubsection{In Vitro Drug Release Studies and Kinetic Analysis}

One of the most important steps in the study of the efficacy of new delivery systems is the in vitro drug release analysis. Topical carriers are an advanced form of powders for which, so far, there are no compendial or standard release techniques and apparatuses [31,32]. Therefore, several in vitro drug release methods have been used: for example, dialysis [8,12,31,69], Franz cells [23,31,40,70], paddle or basket apparatuses [11,71], flow through cells $[8,40]$. Variations in the release profiles between different methodologies could be observed $[8,31,40]$, as the methods are different in their working principles. Therefore, during this study, SAP release from HA and HA-CL MS was evaluated with two different in vitro methods: dialysis and Franz diffusion cells. As the control, diffusion tests of free SAP across dialysis and polyamide filter membranes were performed.

Dialysis is a widely used release technique: microspheres are retained into a membrane, while the drug released diffuses firstly from the carrier to the media inside the membrane, and then to an external compartment. Inevitably, the membrane opposes a resistance to the diffusion of drug molecules. This resistance can be limited by using a membrane with an MWCO smaller than the microcarrier size, but importantly bigger than drug molecular weight [72]. Considering hyaluronan MS size and SAP molecular weight $(358.08 \mathrm{~g} / \mathrm{mol}), 10 \mathrm{kDa}$ MWCO dialysis cassettes were employed in this study. Nevertheless, significant errors were introduced by this release method, as the experimental data did not seem to fully reflect the real release profile of SAP from hyaluronan MS. As previously reported in the literature [72,73], the measured release kinetic seemed to be decreased with respect to the reality: the diffusion rate of free SAP, a highly hydrophilic drug, appeared extremely slow-after $420 \mathrm{~min}$, only the $68.3 \pm 3.1 \%$ of the drug diffused (Figure 8a). Moreover, SAP release profiles from MS appeared controlled by the membranes rather than by the microspheres, as they were almost identical to the diffusion profile of free SAP (Figure 8a). Indeed, a statistical comparison of dialysis data with Moore and Flanner Fit Factors confirmed that all the curves were similar, showing $f_{1}<10$ and $f_{2}>50$ (Table 3). Therefore, in this work, the precise release process and kinetic behavior could not be studied using dialysis release method. Similar drawbacks using dialysis technique have already been described in the literature for procaine hydrochloride release from a polymeric carrier: the actual rate of drug release from the delivery system was faster than the rate of diffusion out of the membrane [72]. These results confirm that dialysis could be an unreliable methodology to study drug release from 
microcarriers, especially when characterized by a rapid release kinetics [72,73]. Taken together, all these considerations and experimental pieces of evidence can be helpful to optimize, in future, the design of drug release studies for microsystems.
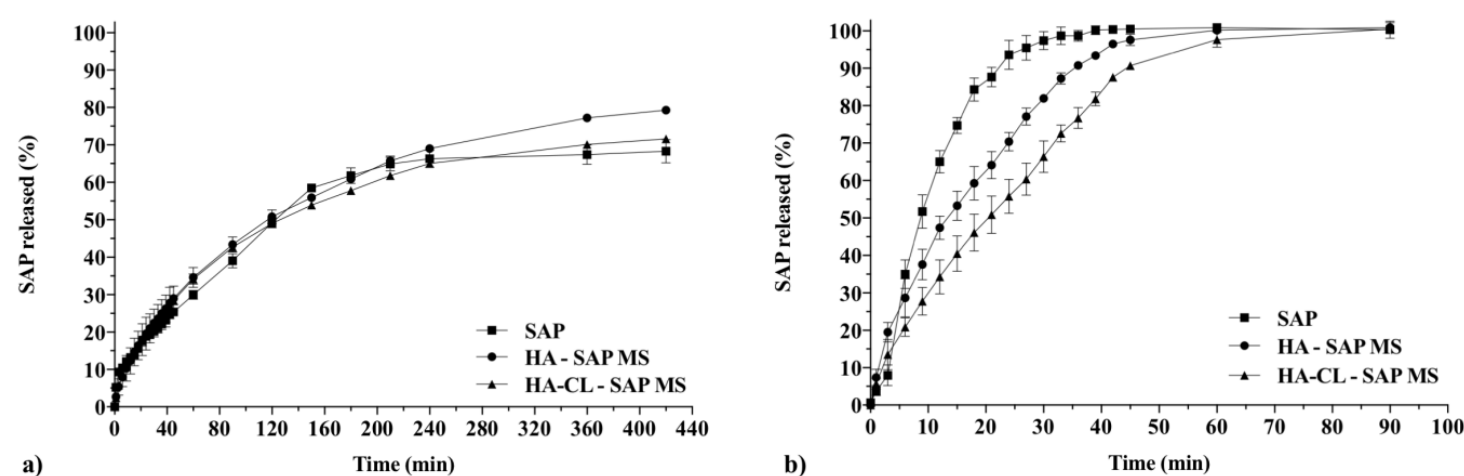

Figure 8. Diffusion profile of SAP as free drug and release profile of SAP from HA and HA-CL MS investigated by dialysis (a) and Franz diffusion cells (b).

Table 3. Similarity factors $\left(f_{2}\right)$ and difference factors $\left(f_{1}\right)$ for free SAP and MS formulations

\begin{tabular}{ccccc}
\hline Release Method & Reference Formulation & Test Formulation & $f_{\mathbf{1}}$ & $f_{\mathbf{2}}$ \\
\hline Dialysis & SAP & HA-SAP MS & 7.9 & 71.4 \\
& SAP & HA-CL-SAP MS & 7.0 & 74.9 \\
& HA-SAP MS & HA-CL-SAP MS & 3.3 & 82.5 \\
\hline \multirow{2}{*}{ Franz diffusion cell } & SAP & HA-SAP MS & 15.4 & 42.7 \\
& SAP & HA-CL-SAP MS & 27.4 & 30.8 \\
& HA-SAP MS & HA-CL-SAP MS & 15.1 & 47.9 \\
\hline
\end{tabular}

Franz diffusion cell tests are probably the most suitable and performed studies to investigate plain drug diffusion and drug release from microparticles intended for dermal and/or mucosal application. Indeed, this model reproduces the conditions encountered on skin and mucosae surface, consenting a slow hydration of the carrier in a humid environment. In vitro release profiles obtained with Franz diffusion cells method were different from those observed with dialysis technique, as displayed by Figure 8. Free SAP diffusion was faster than SAP release from HA MS and HA-CL MS (Figure 8b). More precisely, SAP release from HA-CL MS was significantly extended not only compared to plain SAP but also with respect to HA MS, as proved by Moore and Flanner similarity and difference factors $\left(f_{1}>10\right.$ and $\left.f_{2}<50\right)$ (Table 3$)$. For example, after $30 \mathrm{~min}$, the amount of drug released was $97.4 \pm 2.4 \%$ for plain SAP, versus $81.9 \pm 0.4 \%$ and $66.4 \pm 4.2 \%$ for HA MS and HA-CL MS, respectively (Figure 8). A slower drug release was expected with HA-CL MS, considering the higher molecular weight and the implemented mechanical properties of the crosslinked polymer compared to native HA $[9,16,74]$. The influence of the polymer properties on the release profile was evident, and therefore Franz diffusion cell was found to be a discriminative method to study SAP release kinetic processes.

Among the mathematical templates used to analyze SAP release kinetic from hyaluronan MS, Korsmeyer-Peppas model resulted in the highest $R^{2}$ values when compared to Zero order, First order and Higuchi models, for both the formulations (Table 4). The values of the diffusional exponent $n$ characterizing the release mechanism were 0.709 for HA-SAP MS and 0.712 for HA-CL-SAP MS, suggesting anomalous transport processes $[43,46]$. SAP release from hyaluronan MS was therefore governed not only by drug diffusion but also by polymer swelling and dissolution. Hyaluronan MS containing SAP behaved as swellable devices composed by hydrophilic polymeric matrixes where a water-soluble drug was dispersed: water penetrated into the polymeric networks, causing their disentanglement and swelling. These phenomena decreased hyaluronan concentration, therefore 
enhancing its dissolution at the interface and SAP wettability and diffusion [43,46]. Thus, SAP release was completed in a time frame of about an hour for both the formulations (Figure 8).

Table 4. Correlation coefficient for Zero order, First order, Higuchi, and Korsmeyer-Peppas models for SAP dissolution profiles obtained with Franz diffusion cell method.

\begin{tabular}{ccccc}
\hline \multirow{2}{*}{ Formulation } & \multicolumn{4}{c}{ Correlation Coefficient $\mathbf{R}^{\mathbf{2}}$} \\
\cline { 2 - 5 } & Zero Order & First Order & Higuchi & Korsmeyer-Peppas \\
\hline HA-SAP MS & 0.729 & 0.941 & 0.929 & 0.993 \\
HA-CL-SAP MS & 0.837 & 0.922 & 0.960 & 0.999 \\
\hline
\end{tabular}

\section{Conclusions}

The present study showed, for the first time and with a systematic approach, that HA-CL could be a promising biopolymer to prepare drug-loaded microspheres with a water-in-oil (w/o) emulsification solvent evaporation technique. Appropriate working conditions led to the production of HA-CL MS and HA-CL-SAP MS characterized by almost unimodal size distributions (Span values lower than 3); mean diameter of $13.0 \pm 0.7$ and $9.9 \pm 0.8 \mu \mathrm{m}$, respectively (suitable for dermal application); spherical shape and rough surface; high yield—similar to that of HA MS and HA-SAP MS ( $\approx 85 \%)$. SAP could be more efficiently encapsulated into HA-CL MS (78.8 $\pm 2.6 \%)$ compared to HA-SAP MS $(69.7 \pm 4.6 \%)$. Physical and molecular state, thermal properties, relative moisture stability of HA-CL MS and HA-CL-SAP MS were comparable to those of HA MS and HA-SAP MS. However, a preliminary Franz diffusion cells test displayed a more extended drug release for HA-CL-SAP MS with respect to HA-SAP MS, despite the same kinetic mechanism (contemporaneous drug diffusion and polymer swelling and dissolution). This underlined that the implemented mechanical properties of the novel HA-CL could result in more efficient microsystems, which could be potentially improved, in future, by the addition of excipients able to further slow down drug release. In vitro studies on skin cells are currently performed to explore SAP release/transport across the cells and the bioactivity of HA-CL MS and HA-CL-SAP MS, in order to understand if they effectively improve hydration and re-epithelialization compared to HA MS and HA-SAP MS.

\section{Patent}

Fallacara, A.; Vertuani, S.; Manfredini, S.; Citernesi, U.R. 2018c. Patent Appl. Filed, n. 102018000008192.

Author Contributions: A.F. and S.M. (corresponding author) conceived the study. A.F. designed and performed the experiments, acquired, analyzed, and interpreted the data; wrote the manuscript. F.M. and M.P. contributed to carrying out the experiments, and S.M. participated in the interpretation of the results. S.V. and U.R.C. contributed to revise the manuscript. All authors have given approval to the final version of the manuscript.

Funding: This work was supported by a Ph.D. grant (to Arianna Fallacara) from I.R.A. Srl (Istituto Ricerche Applicate Srl, Usmate-Velate, Monza-Brianza, Italy). The authors thank the University of Ferrara and Ambrosialab s.r.l. (Ferrara, Italy, Grant 2016) for the financial support to the running costs of the study.

Acknowledgments: Authors gratefully acknowledge the Woolcock Institute of Medical Research and Discipline of Pharmacology, Respiratory Technology-Faculty of Medicine and Health, The University of Sydney (431, Glebe, NSW 2037, Australia) - for the use of facilities and instrumentation. The technical assistance of Gabriele Bertocchi (University of Ferrara) for X-ray analysis is gratefully acknowledged, as well as the English revision of Luigi Mastroianni (State Language High School “Giosuè Carducci” Ferrara, Italy).

Conflicts of Interest: The authors declare no conflict of interest. U.R.C. own stocks in I.R.A. srl..The funder had no role in the design of the study; in the collection, analyses, or interpretation of data; in the writing of the manuscript, and in the decision to publish the results.

\section{References}

1. Fallacara, A.; Baldini, E.; Manfredini, S.; Vertuani, S. Hyaluronic Acid in the Third Millennium. Polymers 2018, 10, 701. [CrossRef] 
2. Laurent, T.C.; Laurent, U.G.B.; Fraser, J.R.E. Functions of hyaluronan. Ann. Rheum. Dis. 1995, 54, 429-432. [CrossRef] [PubMed]

3. Liao, Y.H.; Jones, S.A.; Forbes, B.; Martin, G.P.; Brown, M.B. Hyaluronan: Pharmaceutical characterization and drug delivery. Drug Deliv. 2005, 2, 327-342. [CrossRef] [PubMed]

4. Mayol, L.; Quaglia, F.; Borzacchiello, A.; Ambrosio, L.; La Rotonda, M.I. A novel poloxamers/hyaluronic acid in situ forming hydrogel for drug delivery: Rheological, mucoadhesive and in vitro release properties. Eur. J. Pharm. Biopharm. 2008, 1, 199-206. [CrossRef]

5. Benedetti, L.M.; Topp, E.M.; Stella, V.J. Microspheres of hyaluronic acid esters-fabrication methods and in vitro hydrocortisone release. J. Control. Release 1990, 13, 33-41. [CrossRef]

6. Casale, M.; Moffa, A.; Sabatino, L.; Pace, A.; Oliveto, G.; Vitali, M.; Baptista, P.; Salvinelli, F. Hyaluronic acid: Perspectives in the upper aero-digestive tract. A systematic review. PLoS ONE 2015, 10, e0130637. [CrossRef] [PubMed]

7. El Kechai, N.; Geiger, S.; Fallacara, A.; Cañero Infante, I.; Nicolas, V.; Ferrary, E.; Huang, N.; Bochot, A.; Agnely, F. Mixtures of hyaluronic acid and liposomes for drug delivery: Phase behavior, microstructure, and mobility of liposomes. Int. J. Pharm. 2017, 523, 246-259. [CrossRef]

8. Esposito, E.; Menegatti, E.; Cortesi, R. Hyaluronan-based microspheres as tools for drug delivery: A comparative study. Int. J. Pharm. 2005, 288, 35-49. [CrossRef]

9. Fallacara, A.; Manfredini, S.; Durini, E.; Vertuani, S. Hyaluronic acid fillers in soft tissue regeneration. Facial Plast. Surg. 2017, 33, 87-96. [CrossRef]

10. Li, Y.; Han, M.; Liu, T.; Cun, D.; Fang, L.; Yang, M. Inhaled hyaluronic acid microparticles extended pulmonary retention and suppressed systemic exposure of a short-acting bronchodilator. Carbohydr. Polym. 2017, 172, 197-204. [CrossRef]

11. Lim, S.T.; Martin, G.P.; Berry, D.J.; Brown, M.B. Preparation and evaluation of the in vitro drug release properties and mucoadhesion of novel microspheres of hyaluronic acid and chitosan. J. Control. Release $\mathbf{2 0 0 0}$, 66, 281-292. [CrossRef]

12. Saadat, E.; Shakor, N.; Gholami, M.; Dorkoosh, F.A. Hyaluronic acid based micelle for articular delivery of triamcinolone, preparation in vitro and in vivo evaluation. Int. J. Pharm. 2015, 489, 218-225. [CrossRef] [PubMed]

13. Shimojo, A.A.; Pires, A.M.; Lichy, R.; Rodrigues, A.A.; Santana, M.H. The crosslinking degree controls the mechanical, rheological, and swelling properties of hyaluronic acid microparticles. J. Biomed. Mater. Res. A 2015, 103, 730-737. [CrossRef] [PubMed]

14. Ramamurthi, A.; Vesely, I. Smooth muscle cell adhesion on cross-linked hyaluronan gels. J. Biomed. Mater. Res. 2002, 60, 195-205. [CrossRef] [PubMed]

15. Tomihata, K.; Ikada, Y. Preparation of cross-linked hyaluronic acid films of low water content. Biomaterials 1997, 18, 189-195. [CrossRef]

16. Citernesi, U.R.; Beretta, L.; Citernesi, L. Crosslinked Hyaluronic Acid, the Process for the Preparation Thereof and Use Thereof in the Aesthetic Field. Patent WO/2015/007773 A1, 22 January 2015.

17. Fallacara, A.; Vertuani, S.; Panozzo, G.; Pecorelli, A.; Valacchi, G.; Manfredini, S. Novel Artificial Tears Containing Cross-Linked Hyaluronic Acid: An In Vitro Re-Epithelialization Study. Molecules 2017, 22, 2104. [CrossRef] [PubMed]

18. Fallacara, A.; Busato, L.; Pozzoli, M.; Ghadiri, M.; Ong, H.X.; Young, P.M.; Manfredini, S.; Traini, D. Combination of urea-crosslinked hyaluronic acid and sodium ascorbyl phosphate for the treatment of inflammatory lung diseases: An in vitro study. Eur. J. Pharm. Sci. 2018, 120, 96-106. [CrossRef] [PubMed]

19. Albèr, C.; Brandner, B.D.; Björklund, S.; Billsten, P.; Corkery, R.W.; Engblom, J. Effects of water gradients and use of urea on skin ultrastructure evaluated by confocal Raman microspectroscopy. Biochim. Biophys. Acta 2013, 1828, 2470-2478. [CrossRef]

20. Charlton, J.F.; Schwab, I.R.; Stuchell, R. Topical urea as a treatment for non-infectious keratopathy. Acta Ophthalmol. Scand. 1996, 74, 391-394. [CrossRef]

21. Pan, M.; Heinecke, G.; Bernardo, S.; Tsui, C.; Levitt, J. Urea: A comprehensive review of the clinical literature. Dermatol. Online J. 2013, 19, 20392.

22. Degim, Z. Use of microparticulate systems to accelerate skin wound healing. J. Drug Target. 2008, 16, 437-448. [CrossRef] [PubMed] 
23. Abd El-Hameed, M.D.; Kellaway, I.W. Preparation and in vitro characterisation of mucoadhesive polymeric microspheres as intra-nasal delivery systems. Eur. J. Pharm. Biopharm. 1997, 44, 53-60. [CrossRef]

24. Kulkarni, A.D.; Bari, D.B.; Surana, S.J.; Pardeshi, C.V. In vitro, ex vivo and in vivo performance of chitosan-based spray-dried nasal mucoadhesive microspheres of diltiazem hydrochloride. J Drug Deliv. Sci. Technol. 2016, 31, 108-117. [CrossRef]

25. Khan, H.; Akhtar, N.; Ali, A. Assessment of combined ascorbyl palmitate (AP) and sodium ascorbyl phosphate (SAP) on facial skin sebum control in female healthy volunteers. Drug Res. (Stuttg) 2017, 67, 52-58. [CrossRef] [PubMed]

26. Klock, J.; Ikeno, H.; Ohmori, K.; Nishikawa, T.; Vollhardt, J.; Schehlmann, V. Sodium ascorbyl phosphate shows in vitro and in vivo efficacy in the prevention and treatment of acne vulgaris. Int. J. Cosmet. Sci. 2005, 27, 171-176. [CrossRef] [PubMed]

27. Amirlak, B.; Mahedia, M.; Shah, N. A clinical evaluation of efficacy and safety of hyaluronan sponge with vitamin C versus placebo for scar reduction. Plast. Reconstr. Surg. Glob. Open 2016, 4, e792. [CrossRef] [PubMed]

28. Spiclin, P.; Homar, M.; Zupancic-Valant, A.; Gasperlin, M. Sodium ascorbyl phosphate in topical microemulsions. Int. J. Pharm. 2003, 256, 65-73. [CrossRef]

29. Wetton, R.E.; Whorlow, R.W. Polymer Systems: Deformation and Flow; Macmillan: London, UK, 1968; ISBN 100333062035.

30. Couarraze, G.; Grossiord, J.L. Initiation à la Rhéologie; TEC \& DOC: Paris, France, 2000; ISBN 2-7430-0285-9.

31. Balzus, B.; Colombo, M.; Sahle, F.F.; Zoubari, G.; Staufenbiel, S.; Bodmeier, R. Comparison of different in vitro release methods used to investigate nanocarriers intended for dermal application. Int. J. Pharm. 2016, 513, 247-254. [CrossRef]

32. Lusina Kregar, M.; Durrigl, M.; Rozman, A.; Jelcic, Z.; Cetina-Cizmek, B.; Filipovic-Grcic, J. Development and validation of an in vitro release method for topical particulate delivery systems. Int. J. Pharm. 2015, 485, 202-214. [CrossRef]

33. Schlupp, P.; Blaschke, T.; Kramer, K.D.; Höltje, H.D.; Mehnert, W.; Schäfer-Korting, M. Drug release and skin penetration from solid lipid nanoparticles and a base cream: A systematic approach from a comparison of three glucocorticoids. Skin Pharmacol. Physiol. 2011, 24, 199-209. [CrossRef]

34. Zoubari, G.; Staufenbiel, S.; Volz, P.; Alexiev, U.; Bodmeier, R. Effect of drug solubility and lipid carrier on drug release from lipid nanoparticles for dermal delivery. Eur. J. Pharm. Biopharm. 2017, 110, $39-46$. [CrossRef] [PubMed]

35. Moore, H.H.; Flanner, J.W. Mathematical comparison of dissolution profiles. Pharm. Technol. 1996, 20, 64-74.

36. Food and Drug Administration. Guidance for Industry; Dissolution Testing on Immediate Release Solid Oral Dosage Forms; FDA: Rockville, MD, USA, 1997.

37. Cirri, M.; Roghi, A.; Valleri, M.; Mura, P. Development and characterization of fast-dissolving tablet formulations of glyburide based on solid self-microemulsifying systems. Eur. J. Pharm. Biopharm. 2016, 104, 19-29. [CrossRef] [PubMed]

38. Ong, H.X.; Traini, D.; Bebawy, M.; Young, P.M. Epithelial Profiling of Antibiotic Controlled Release Respiratory Formulations. Pharm. Res. 2011, 28, 2327-2338. [CrossRef] [PubMed]

39. Pozzoli, M.; Traini, D.; Young, P.M.; Sukkar, M.B.; Sonvico, F. Development of a Soluplus budesonide freeze-dried powder for nasal drug delivery. Drug Dev. Ind. Pharm. 2017, 43, 1510-1518. [CrossRef] [PubMed]

40. Salama, R.O.; Traini, D.; Chan, H.K.; Young, P.M. Preparation and characterisation of controlled release co-spray dried drug-polymer microparticles for inhalation 2: Evaluation of in vitro release profiling methodologies for controlled release respiratory aerosols. Eur. J Pharm. Biopharm. 2008, 70, 145-152. [CrossRef] [PubMed]

41. Costa, P.; Sousa Lobo, J.M. Modeling and comparison of dissolution profiles. Eur. J. Pharm. Sci. 2001, 13, 123-133. [CrossRef]

42. Higuchi, T. Rate of release of medicaments from ointment bases containing drugs in suspension. J. Pharm. Sci. 1961, 50, 874. [CrossRef]

43. Arifin, D.Y.; Lee, L.Y.; Wang, C.H. Mathematical modelling and simulation of drug release from microspheres: Implication to drug delivery systems. Adv. Drug Deliv. Rev. 2006, 58, 1274-1325. [CrossRef]

44. Korsmeyer, R.W.; Peppas, N.A. Effect of the morphology of hydrophilic polymeric matrices on the diffusion and release of water-soluble drugs. J. Membr. Sci. 1981, 9, 211-227. [CrossRef] 
45. Peppas, N.A. Analysis of fickian and non-fickian drug release from polymers. Pharm. Acta Helv. 1985, 60, 110-111. [PubMed]

46. Singhvi, G.; Singh, M. Review: In-vitro drug release characterization models. Int. J. Pharm. Sci. Res. 2011, 2, $77-84$.

47. Liu, Z.; Li, X.; Xiu, B.; Duan, C.; Li, J.; Zhang, X.; Yang, X.; Dai, W.; Johnson, H.; Zhang, H.; et al. A novel and simple preparative method for uniform-sized PLGA microspheres: Preliminary application in antitubercular drug delivery. Colloids Surf. B Biointerfaces 2016, 145, 679-687. [CrossRef] [PubMed]

48. Falcone, S.J.; Palmeri, D.M.; Berg, R.A. Rheological and cohesive properties of hyaluronic acid. J. Biomed. Mater. Res. A 2006, 76, 721-728. [CrossRef] [PubMed]

49. Collins, N.M.; Birkinshaw, C. Physical properties of crosslinked hyaluronic acid hydrogels. J. Mater. Sci. Mater. Med. 2008, 19, 3335-3343. [CrossRef] [PubMed]

50. Ré, M.A.; Messias, L.S.; Schettini, H. The influence of the liquid properties and the atomizing conditions on the physical characteristics of the spray-dried ferrous sulfate microparticles. In Proceedings of the 14th International Drying Symposium (IDS 2004), São Paulo, Brazil, 22-25 August 2004; pp. 1174-1181.

51. Gatej, I.; Popa, M.; Rinaudo, M. Role of $\mathrm{pH}$ on hyaluronan behavior in aqueous solution. Biomacromolecules 2005, 6, 61-67. [CrossRef] [PubMed]

52. Maleki, A.; Kjoniksen, A.; Nystrom, B. Effect of $\mathrm{pH}$ on the behavior of hyaluronic acid in dilute and semidilute aqueous solutions. Macromol. Symp. 2008, 274, 131-140. [CrossRef]

53. Bari, E.; Arciola, C.R.; Vigani, B.; Crivelli, B.; Moro, P.; Marrubini, G.; Sorrenti, M.; Catenacci, L.; Bruni, G.; Chlapanidas, T.; et al. In vitro effectiveness of microspheres based on silk sericin and Chlorella vulgaris or Arthrospira platensis for wound healing applications. Materials (Basel) 2017, 10, 983. [CrossRef] [PubMed]

54. Ranjan, S.; Fontana, F.; Ullah, H.; Hirvonen, J.; Santos, H.A. Microparticles to enhance delivery of drugs and growth factors into wound sites. Ther. Deliv. 2016, 7, 711-732. [CrossRef] [PubMed]

55. Anonymous. Benzoyl peroxide microsphere formulations: What is the science supporting microsphere vehicle technology and clinical use? J. Clin. Aesthet. Dermatol. 2009, 2, 46-54.

56. Vertuani, S.; Cvetkovska, A.D.; Zauli, S.; Virgili, A.; Manfredini, S.; Bettoli, V. The topical vehicle as a key factor in the management of the psoriatic patients' therapy. G. Ital. Dermatol. Venereol. 2013, 148, 679-685.

57. Klug, H.P.; Alexander, L.E. X-ray Diffraction Procedures for Polycrystalline and Amorphous Materials, 2nd ed.; John Wiley and Sons: New York, NY, USA, 1974; ISBN 978-0-471-49369-3.

58. Siepmann, J.; Peppas, N.A. Modeling of drug release from delivery systems based on hydroxypropyl methylcellulose. Adv. Drug Deliv. Rev. 2001, 48, 139-157. [CrossRef]

59. Yang, S.C.; Zhu, J.B. Preparation and characterization of camptothecin solid lipid nanoparticles. Drug Dev. Ind. Pharm. 2002, 28, 265-274. [CrossRef] [PubMed]

60. Moyano, M.A.; Broussalis, A.M.; Segall, A.I. Thermal analysis of lipoic acid and evaluation of the compatibility with excipients. J. Therm. Anal. Calorim. 2010, 99, 631-637. [CrossRef]

61. Collins, M.N.; Birkinshaw, C. Comparison of the effectiveness of four different crosslinking agents with hyaluronic acid hydrogel films for tissue-culture applications. J. Appl. Polym. Sci. 2007, 104, 3183-3191. [CrossRef]

62. Kafedjiiski, K.; Jetti, R.K.; Föger, F.; Hoyer, H.; Werle, M.; Hoffer, M.; Bernkop-Schnürch, A. Synthesis and in vitro evaluation of thiolated hyaluronic acid for mucoadhesive drug delivery. Int. J. Pharm. 2007, 343, 48-58. [CrossRef] [PubMed]

63. Lapcik, L.; Otyepkovà, E.; Lapcikovà, B.; Otyepka, M.; Vlcek, J.; Kupskà, I. Physicochemical analysis of hyaluronic acid powder for cosmetic and pharmaceutical processing. In Hyaluronic acid for biomedical and pharmaceutical applications, 1st ed.; Collins, M.N., Ed.; Smithers Rapra Technology: Shropshire, UK, 2014; pp. 89-101, ISBN 109781909030770.

64. Lewandowska, K.; Sionkowska, A.; Grabska, S.; Kaczmarek, B. Surface and thermal properties of collagen/hyaluronic acid blends containing chitosan. Int. J. Biol. Macromol. 2016, 92, 371-376. [CrossRef] [PubMed]

65. Réeff, J.; Gaignaux, A.; Goole, J.; De Vriese, C.; Amighi, K. New sustained-release intraarticular gel formulations based on monolein for local treatment of arthritic diseases. Drug Dev. Ind. Pharm. 2013, 39, 1731-1741. [CrossRef]

66. Albèr, C.; Engblom, J.; Falkman, P.; Kocherbitov, V. Hydration of hyaluronan: Effects on structural and thermodynamic properties. J. Phys. Chem. B 2015, 119, 4211-4219. [CrossRef] 
67. Panagopoulou, A.; Vázquez Molina, J.; Kyritsis, A.; Monleón Pradas, M.; Vallés Lluch, A.; Gallego Ferrer, G.; Pissis, P. Glass Transition and Water Dynamics in Hyaluronic Acid Hydrogels. Food Biophys. 2013, 8, 192-202. [CrossRef]

68. Servaty, R.; Schiller, J.; Binder, H.; Arnold, K. Hydration of polymeric components of cartilage-An infrared spectroscopic study on hyaluronic acid and chondroitin sulfate. Int. J. Biol. Macromol. 2001, 28, 121-127. [CrossRef]

69. Montenegro, L.; Trapani, A.; Fini, P.; Mandracchia, D.; Latrofa, A.; Cioffi, N.; Chiarantini, L.; Giusi, G.P.; Brundu, S.; Puglisi, G. Chitosan nanoparticles for topical co-administration of the antioxidants glutathione and idebenone: Characterization and in vitro release. Br. J. Pharm. Res. 2014, 4, 2387-2406. [CrossRef]

70. Alves, A.C.; Ramos, I.I.; Nunes, C.; Magalhães, L.M.; Sklenárová, H.; Segundo, M.A.; Lima, J.L.F.C.; Reis, S. On-line automated evaluation of lipid nanoparticles transdermal permeation using Franz diffusion cell and low-pressure chromatography. Talanta 2016, 146, 369-374. [CrossRef] [PubMed]

71. Dürrigl, M.; Kwokal, A.; Hafner, A.; Šegvi Klari, M.; Dumicic, A.; Cetina-Cižmek, B.; Filipovic-Grcic, J. Spray dried microparticles for controlled delivery of mupirocin calcium: Process-tailored modulation of drug release. J. Microencapsul. 2011, 28, 108-121. [CrossRef] [PubMed]

72. Moreno-Bautista, G.; Tam, K.C. Evaluation of dialysis membrane process for quantifying the in vitro drug-release from colloidal drug carriers. Colloids Surf. A Physicochem. Eng. Asp. 2011, 389, 299-303. [CrossRef]

73. Zambito, Y.; Pedreschi, E.; Di Colo, G. Is dialysis a reliable method for studying drug release from nanoparticulate systems?-A case study. Int. J. Pharm. 2012, 434, 28-34. [CrossRef] [PubMed]

74. Garti, N. Delivery and Controlled Release of Bioactives in Foods and Nutraceuticals, 1st ed.; Woodhead Publishing: Sawston, UK, 2008; p. 496, ISBN 978-1-84569-145-5.

(C) 2018 by the authors. Licensee MDPI, Basel, Switzerland. This article is an open access article distributed under the terms and conditions of the Creative Commons Attribution (CC BY) license (http:/ / creativecommons.org/licenses/by/4.0/). 